doi: $10.15407 /$ ujpe62.03.0208

V.V. HLADKOVSKIY, O.A. FEDOROVICH

Institute for Nuclear Research, Nat. Acad. of Sci. of Ukraine

(47, Nauky Ave., Kyiv 03028, Ukraine; e-mail: v.glad2010@yandex.ua)

\title{
SPECTROSCOPIC STUDIES OF RF DISCHARGE PLASMA AT PLASMA-CHEMICAL ETCHING OF GALLIUM NITRIDE EPITAXIAL STRUCTURES
}

\begin{abstract}
The results of experimental researched dealing with the bias voltage influence on the evolution of spectra emitted by plasma at the etching of gallium nitride in a plasma-chemical reactor with the controlled magnetic field are reported. At high bias voltage values above-250 V, there appear lines in the plasma emission spectra which belong to the excited atoms of the material of a working electrode. Under the influence of a negative potential, the active electrode is sputtered, and metal ions are redeposited onto its surface, which results in the lower etching rate.

Keywords: bias voltage, plasma-chemical etching, sputtering, plasma-chemical reactor, radio-frequency discharge, optical spectroscopy.
\end{abstract}

\section{Introduction}

Gallium nitride $(\mathrm{GaN})$ is a direct-gap semiconductor with an energy gap width of $3.4 \mathrm{eV}$ at a temperature of $300 \mathrm{~K}$. A unique combination of its physicochemical properties - namely, high thermal (at $T>$ $>2500 \mathrm{~K}$ [1] $)$ and radiation $\left(10^{5}-2 \times 10^{6} \mathrm{rad}[2]\right)$ stabilities together with chemical inertness and high thermal conductivity $(130 \mathrm{~W} /(\mathrm{m} \mathrm{K})$ - is promising for GaN applications in various domains of electronics.

Devices on the basis of GaN are capable to operate in much wider exploitation intervals than devices fabricated on the basis of traditional semiconductor substances. One of the advantages of gallium nitride over other materials for electronics is the highest breakdown electric field strength. Namely, it equals $3.3 \mathrm{~V} / \mathrm{cm}$, which is 11 times as high as for $\mathrm{Si}$ $(0.3 \mathrm{~V} / \mathrm{cm})$ and 8 times for GaAs $(0.4 \mathrm{~V} / \mathrm{cm})$. Therefore, gallium nitride is a promising material both for researchers and for its practical applications in the space, opto-, and power electronics.

(C) V.V. HLADKOVSKIY, O.A. FEDOROVICH, 2017
Conditions for plasma-chemical etching (PCE) of GaN substantially differ from those for other semiconductor materials. This fact is first associated with the high chemical inertness of this substance and strong chemical bonds in its crystal lattice: $E_{d}(\mathrm{Ga})=$ $=20.5 \mathrm{eV}$ and $E_{d}(\mathrm{~N})=10.8 \mathrm{eV}$ [3], which considerably differs from widely used silicon, whose binding energy in the crystal lattice amounts to only $E_{d}(\mathrm{Si})=$ $=1.8 \mathrm{eV}$. Second, the application of fluorinecontaining gases, which are used rather widely at $\mathrm{PCE}$, is not expedient, because they do not form volatile compounds with gallium, and probable products of their reaction $\left(\mathrm{GaF}_{3}\right)$ have a sublimation temperature of $1273 \mathrm{~K}$. As a result, the substantial heating of treated specimens is required, which can give rise to a destruction of a metal mask (in our case, $\quad 0.5-1 \mu \mathrm{m})$. Therefore, tetrachloromethane, $\mathrm{CCl}_{4}$, was selected as a working gas. The products of possible reactions between the atoms in $\mathrm{CCl}_{4}$ molecules and GaN are formed on the surface of the latter as the $\mathrm{GaCl}_{3}$ and $\mathrm{GaCl}_{2}$ compounds with a sublimation temperature of 474 and $808 \mathrm{~K}$,

ISSN 2071-0194. Ukr. J. Phys. 2017. Vol. 62, No. 3 
respectively [4]. However, this gas is not the most suitable, because the atomic chlorine has a high chemical activity, which results in a reduction of the operating time for an applied equipment.

Another important aspect, which was pointed out in work [5], is the formation of carbon and chlorinecarbon layers on the specimen surface. The appearance of this layer, as well as its further growth, reduces the etching rate and even stops it. In order to prevent the emergence of the carbon and chlorine-carbon layers at PCE, the mixtures of $\mathrm{CCL}_{4}$ with other gases - in particular, oxygen - are used $[4,6]$. The addition of oxygen results in the appearance of $\mathrm{Cl}_{2}, \mathrm{CO}$, and $\mathrm{COCl}_{2}$ molecules owing to a high chemical activity of saturated radicals that are formed during the dissociation and contain atomic and molecular oxygen [4].

For a high-quality plasma-chemical etching and a good reproducibility of the process, it is important to control the discharge parameters and the qualitative composition of plasma. A promising technique for this purpose is the optical emission spectroscopy. There are very little experimental data on the influence of the ion energy on the evolution of spectra emitted by plasma in the tetrachloromethane atmosphere, and we did not manage to find them in available sources. From the available body of information, it follows that the major components observed in the emission spectra and mass spectrograms are $\mathrm{CN}, \mathrm{C}_{2}$ $[4,7], \mathrm{Cl}, \mathrm{Cl}_{2}, \mathrm{Cl}^{+}[4,8], \mathrm{C}_{2}^{+}, \mathrm{C}^{+}, \mathrm{Cl}_{2}^{+}, \mathrm{CCl}_{3}, \mathrm{CCl}_{2}^{+}$, $\mathrm{CCl}^{+}$, and so forth $[4,9]$.

Therefore, the optimization of the plasma-chemical etching of $\mathrm{GaN}$ and the spectroscopic researches of plasma remain to be a challenging task nowadays. Those researches are useful not only to control the process of plasma-chemical etching, but also to understand the kinetics of physico-chemical processes running in chemically active plasma. In this work, we report the results of our qualitative analysis concerning the dependence of plasma emission spectra obtained at the etching of GaN on the bias voltage, provided that the other plasma parameters remain fixed.

\section{Experimental Results}

Gallium nitride was etched in a plasma-chemical reactor (PCR) with closed electron drift. The discharge in a PCR chamber was formed in a varied magnetic field located between two electrodes and crossed with an electric field. The first electrode was active. The RF
(13.56 MHz) voltage obtained from the main power source was applied to it. The electrode was fabricated from stainless steel and has form of a trihedral prism, which was cooled by flowing water. The prism faces $110 \times 350 \mathrm{~mm}^{2}$ in dimensions were used to mount treated specimens. The grounded cylindrical reactor vessel served as the second electrode. It was also fabricated from stainless steel and cooled by flowing water. The magnetic field was created with the use of three coils. If the coils were connected in phase, a negative autobias voltage from 20 to $160 \mathrm{~V}$ emerged in the discharge. If the upper and lower coils were connected in antiphase to the middle one, the negative autobias voltage amounted to $160-700 \mathrm{~V}$.

The mirror configuration of the magnetic field made it possible to increase the ionization degree of the working gas in the interelectrode space and to reduce plasma losses, which arose because the diffusiondriven electrons hit the grounded electrode. Provided the mirror configuration of the magnetic field, the magnetic field strength remained constant along the whole length of the working prism face. The working gas was fed symmetrically into the upper part of PCR and evacuated with the use of an oil-vapor diffusion pump of the type N-2T and a high-pressure vacuum pump UVH-14-066, which allowed us to obtain vacuum of an order of $10^{-6}$ Torr. The following external parameters of the discharge, which were required to reproduce discharge conditions and PCE results, were monitored: the gas consumption, discharge current, voltage drop across the discharge, and currents in the magnetic field coils. The more complete description of operating modes and the installation setup can be found in works $[10,11]$. To generate a chemically active plasma, an RF generator with a frequency of $13.56 \mathrm{MHz}$ and a power of $4 \mathrm{~kW}$ was used. The controlled magnetic field allowed us to regulate the autobias voltage and, accordingly, the energy of ions from 20 to $700 \mathrm{eV}$ [11].

Gallium nitride specimens $10 \times 10 \mathrm{~mm}^{2}$ in dimensions were treated in the $\mathrm{CCl}_{4}$ atmosphere with impurities of other gases at a pressure of 0.02 Torr and a discharge current of $10 \mathrm{~A}$. The bias voltage was regulated from -100 to $-600 \mathrm{~V}$. Besides the variation of other discharge plasma parameters, we used an additional power source connected through special filters to the active and grounded electrodes in order to control the bias voltage and, accordingly, the energy of charged particles. 
The etching of the material is driven by chemical reactions between free atoms and radicals formed in gas-discharge plasma and atoms at the surface of the treated material and by physical sputtering of the material by accelerated ions of chemically active gases. One of the important parameters of the plasma-chemical etching is the rate of this process. In works $[4,12]$, it was shown that one of the parameters that affect the PCE rate is the autobias voltage, $U_{\text {bias }}$. The autobias voltage is a dc voltage arising between the active and grounded electrodes at RF discharges in working gases. It emerges owing to different mobilities (diffusion rates) of electrons and ions in $\mathrm{RF}$ discharge plasma, as well as different electrode areas. The autobias voltage depends on the strength and configuration of the magnetic field [12] and on the discharge current magnitude.

If materials are treated at high negative values of bias voltage, ions are drawn out from the plasma volume and interact with the material of electrodes. As a result, they acquire rather a high kinetic energy and can knock out atoms from the electrode surface. Those atoms get into the discharge gap, which affects the physico-chemical properties of discharge plasma. Metal atoms from plasma can be deposited as impurities on the surface of treated materials. This process results in a reduction of the etching rate, because some atoms deposited on the specimen surface do not form volatile compounds, which could be pumped out from PCR using the vacuum pump [13].

Therefore, the researches of $\mathrm{RF}$ discharge plasma at various bias voltages can be useful for the optimization of technological processes applied at PCE of materials. The radiation spectra were registered in the wavelength interval $\lambda=300-800 \mathrm{~nm}$ on a modernized universal complex for spectral computations UCSC-23. The complex included a monochromator MDR-23 with a reverse dispersion of $1.3 \mathrm{~nm} / \mathrm{mm}$ and a diffraction grating with $N=1200$ line $/ \mathrm{mm}$.

Radiation emitted by RF discharge plasma, after having passed through a quartz lens condenser with a focal length of $10 \mathrm{~cm}$, was focused on the end face of a quartz lightguide, which was mounted at the lens focus. The light beam passed through the 10-m lightguide with minimum losses and diverged at its output. Its radiation passed through a lens with a focal length of $5 \mathrm{~cm}$ and was focused on the monochromator input slit. The application of an optical waveguide was associated with the neces- sity to transmit light radiation to the monochromator through a large distance (10 to $40 \mathrm{~m}$ ). It was done to isolate high-sensitive devices from high-frequency inductions. Afterward, the light flux passed through a diffraction grating and, after its spectral decomposition and focusing, was directed from the monochromator output slit onto the cathode of a photoelectron multiplier PEM-100. The electric signal generated by the photomultiplier arrived at the input of a dc amplifier. A standard amplifier in the UCSC23 complex turned out very sensitive to temperature variations and had a large zero drift. Therefore, it was changed to a micro/nano ammeter F-196, in which microcircuits with signal modulation and demodulation were used. This substitution allowed the variation of the amplification coefficient with ambient temperature changes to be minimized. From the amplifier output, the signal arrived at an analog-digital converter. After the signal was transformed into a code, it was directed to the control computer.

The spectra were scanned with the use of a stepping motor, which rotated the diffraction grating of a monochromator. The step of grating rotation for the consecutive read out of the signal could be regulated. The wavelength calibration was carried out with the help of a helium-neon laser with $\lambda=$ $=632.8 \mathrm{~nm}$. Either the spectra were recorded on a chart strip with the simultaneous printing of wavelengths or the data were registered electronically in the digital form. The emission spectral lines of excited atoms and molecular bands were identified with the use of the tables of spectral lines and bands [14-16] and the NIST database.

The emission spectrum of RF discharge plasma in tetrachloromethane, which was used for the plasmachemical etching of GaN, registered at the bias voltage $U_{\text {bias }}=-100 \mathrm{~V}$ is depicted in Fig. 1. In the near ultra-violet region of the spectrum, the intensive molecular bands of cyanogen $(\mathrm{CN})$ at 388.3 and $421.6 \mathrm{~nm}$, bands of the Deslandres-d'Azambuja system $\left(\mathrm{C}_{2}\right)$ at 406.8 and $385.2 \mathrm{~nm}$, and an intensive Swan band $\left(\mathrm{C}_{2}\right)$ at $516.5 \mathrm{~nm}$ were revealed. As one can see from this figure, the spectrum also demonstrates the most intensive emission lines of atomic chlorine $(\mathrm{Cl})$ with excitation energies from 10.59 to $11.74 \mathrm{eV}$. The chlorine lines at 725.6, 741.1, and $754.7 \mathrm{~nm}$ are marked in the NIST database as the most intensive ones. However, the intensities of lines at 438.9 and $439.0 \mathrm{~nm}$ are several times higher that 


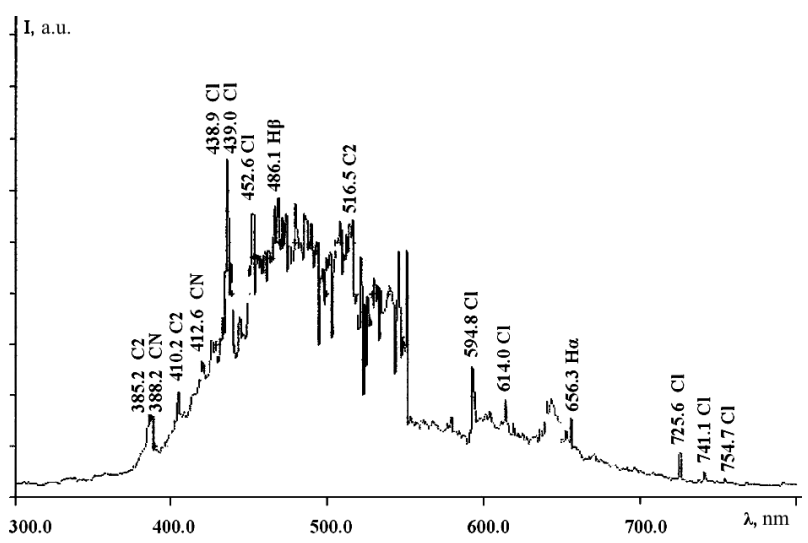

Fig. 1. Emission spectrum of RF discharge plasma in tetrachloromethane at the etching of GaN with $U_{\text {bias }}=-100 \mathrm{~V}$

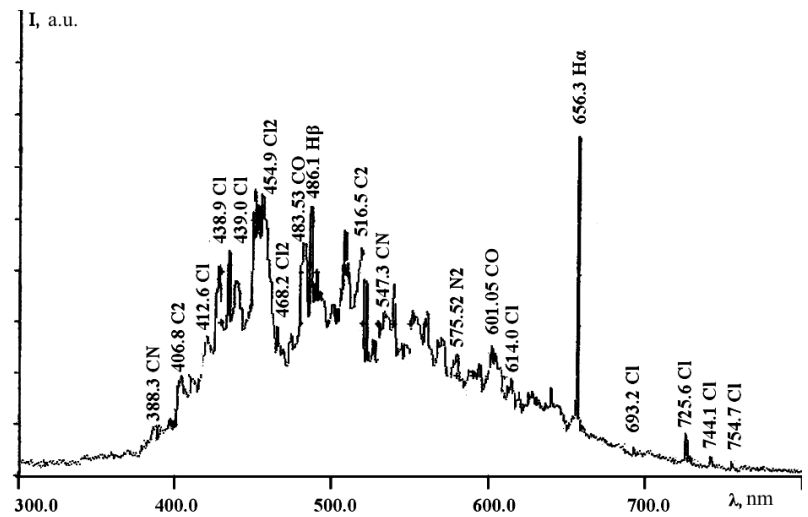

Fig. 2. The same as in Fig. 1, but for $U_{\text {bias }}=-200 \mathrm{~V}$

the intensities of chlorine lines observed in the spectrogram. The reduction of the heights of chlorine line peaks in the infra-red spectral region relatively to the lines in the blue spectral region is explained by a nonuniform spectral sensitivity of the PEM-100 amplifier, in particular, its low sensitivity in the red and infrared spectral regions.

At a higher bias voltage of $-200 \mathrm{~V}$, the emission spectrum becomes a little more complicated (Fig. 2). As in the previous case where $U_{\text {bias }}=$ $=-100 \mathrm{~V}$, the most intensive lines of atomic chlorine again manifest themselves in the spectrum. However, a large number of molecular bands belonging to the dissociation products of working gases were also revealed in the interval from $\lambda=440 \mathrm{~nm}$ to $\lambda=$ $=625 \mathrm{~nm}$. Among them, the $\mathrm{Cl}_{2}$ lines at 454.9 and $468.2 \mathrm{~nm}$ are the most intensive. The Swan bands for $\mathrm{C}_{2}$ at $516.5 \mathrm{~nm}, \mathrm{CN}$ at $547.3 \mathrm{~nm}, \mathrm{~N}_{2}$ at $575.52 \mathrm{~nm}$, as

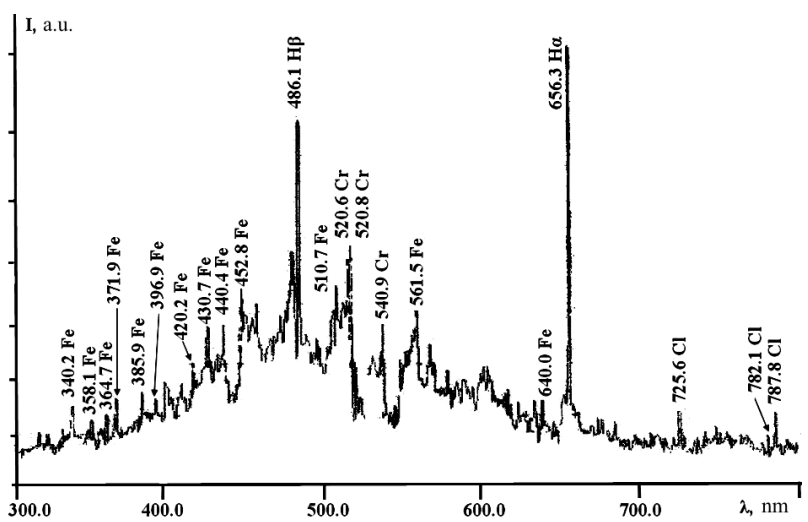

Fig. 3. The same as in Fig. 1 , but for $U_{\text {bias }}=-400 \mathrm{~V}$

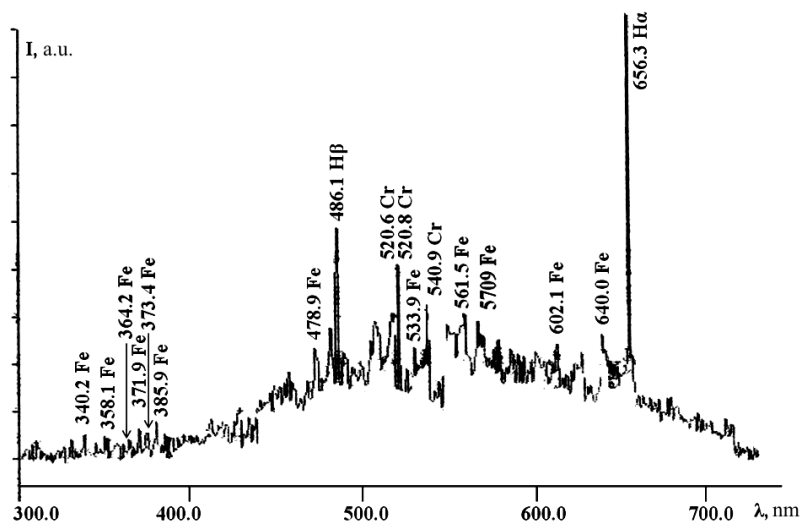

Fig. 4. The same as in Fig. 1 , but for $U_{\text {bias }}=-600 \mathrm{~V}$

well as a CO triplet at 598.07, 603.7, and $601.05 \mathrm{~nm}$, were also revealed.

An interesting aspect is the intensity growth of $\mathrm{H}_{\alpha}$ and $\mathrm{H}_{\beta}$ lines, which can be associated with increase of the concentration of atomic hydrogen in the plasma volume due to a possible desorption of water vapor from the internal surface of the walls of a PCR chamber. The intensities of chlorine lines at $\lambda=725.6$, 741.1 , and $754.7 \mathrm{~nm}$ in the long-wave spectral region are close to each other, as it was in the previous case. Our results correlate with the results obtained in work [4], in which the mass spectra of the products of chemical reactions and dissociation that run in the PCR when etching the gallium nitride structures in $\mathrm{CCl}_{4}$ plasma are presented. The mass spectrograms obtained in the course of etching demonstrate the peaks of ions $\mathrm{CCl}_{3}^{+}, \mathrm{CCl}_{2}^{+}, \mathrm{Cl}_{2}^{+}, \mathrm{CN}^{+}, \mathrm{CO}^{+}$, and others. 
When the bias voltage was increased further to $-400 \mathrm{~V}$ (Fig. 3), it was found that, first, the $\mathrm{Cl}$ lines were almost absent from the spectrum, except for the most intensive ones in the long-wave spectral region; and, second, a considerable number of lines emitted by excited atoms of the metals of electrodes were revealed. Among them, the most noticeable were the intensive lines of iron $(\mathrm{Fe})$ in the near ultra-violet region. The resonance lines of $\mathrm{Cr}$ at 520.6 and $520.8 \mathrm{~nm}$, as well as the line at $540.9 \mathrm{~nm}$, which are used in the emission spectral analysis of atomic materials to determine the amount of impurities [17], were also observed. By intensity, they exceeded even the most intensive Fe lines. Now, however, the plasma spectrum contained no molecular bands belonging to the dissociation products of working gases, which were observed in two first cases.

Figure 4 exhibits the emission spectrum of RF discharge plasma registered at a bias voltage of $-600 \mathrm{~V}$. The spectrum contains absolutely no $\mathrm{Cl}$ lines and molecular bands, but includes a considerable number of $\mathrm{Fe}$ and $\mathrm{Cr}$ atomic lines. As in the case where $U_{\text {bias }}=-400 \mathrm{~V}$, the most pronounced are lines in the near ultra-violet region. The difference from the previous case consists in that the number of lines belonging to iron atoms increases in the orange spectral region. In the plasma spectrum, there are no lines of $\mathrm{Ti}$, which was a component of a working electrode. It is so because Ti can form volatile compounds with $\mathrm{Cl}$, which were pumped out from the reactor volume. The spectrum also demonstrates the absence of Ni lines, since $\mathrm{Ni}$ is badly sputtered. This result is confirmed by X-ray researches of the surface of silicon wafers after their treatment in PCR at various bias voltages $[13,18]$. Owing to this property, nickel is used for protective masks at the plasma-chemical etching [4].

The analysis of the measured emission spectra showed that the plasma composition changes qualitatively with the growth of the average energy of ions interacting with the treated specimen and the electrode surface. Metal lines are mainly observed at high energies. As an example, the Fe line at $371.9 \mathrm{~nm}$ in the near ultra-violet region is one of the most intensive lines of this element. For $\mathrm{Cl}$, this role is played by a line at $725.6 \mathrm{~nm}$ in the infra-red region. According to the Einstein-Boltzmann relation, the iron emission line intensity exceeds that of the chlorine line by a factor of 14 , because the excitation energy equals $3.3 \mathrm{eV}$ for the iron atom and $10.6 \mathrm{eV}$ for the chlorine one. Therefore, iron lines manifest themselves much easier in the emission spectra, because the energy levels of iron atoms are more populated by electrons in comparison with those of chlorine atoms at the same plasma temperature. Hence, in this case, the smaller number of excited metal atoms with lower excitation potentials emit more strongly than the larger number of chlorine atoms with high excitation energies. By virtue of the low sensitivity of an PEM-100 in the infra-red spectral region, this difference manifests itself even more strongly at the spectrum registration.

\section{Conclusions}

At high bias voltages, the lines of excited atoms belonging to the dissociation products of working gases disappear from the emission spectra. Instead, there appear the most intensive lines belonging to the excited atoms of the elements of the working electrode. At bias voltages between the electrodes above $-250 \mathrm{~V}$, the working electrode is intensively sputtered, which results in a drastic decrease of the material etching rate. Therefore, GaN and other substances have to be etched at bias voltages below $-250 \mathrm{~V}$.

1. T. Harafuji, J. Kawamura. Molecular dynamics simulation for evaluating melting point of wurtzite-type GaN crystal. Appl. Phys. 96, 2501 (2004) [DOI: 10.1063/1.1772878].

2. A.E. Belyaev, N.I. Klyui, R.V. Konakova et al. Electroreflectance study of the effect of $\gamma$ radiation on the optical properties of epitaxial GaN films. Fiz. Tekh. Poluprovodn. 46/3, 317 (2012) (in Russian).

3. D.C. Look, D.C. Reynolds, J.W. Hemsky, J.R. Sizelove et al. Defect donor and acceptor in GaN. Phys. Rev. Lett. 79, 2273 (1997) [DOI: 10.1103/PhysRevLett.79.2273].

4. A.G. Borisenko, B.P. Polozov, O.A. Fedorovich et al. Plasmochemical etching of epitaxial nitride gallium structures. Tekhnol. Konstr. Élektron. Apparat. No. 6, 42 (2005) (in Russian).

5. R.A. Gottscho, G. Smolinsky, R.H. Burton. Carbon tetrachloride plasma etching of GaAs and InP: A kinetic study utilizing nonperturbative optical techniques. J. Appl. Phys. 53, 5908 (1982) [DOI: 10.1063/1.331433].

6. H.J. Tiller, R. Göbel, S. Ustinowa, T. Kloss. Mass spectroscopic product analysis. An investigation of $\mathrm{CCl}_{4}$ plasma. Influence of plasma conditions and gas admixture on the decomposition products. Int. J. Mass Spectr. Ion Proc. 59, 143 (1984) [DOI: 10.1016/0168-1176(84)85091-0].

7. O. Jasek, J. Janca, M. Klima. Synthesis of fullerenes by radiofrequency plasma discharges. In Proceedings of 14 th International Symposium on Plasma Chemistry (Praha, 1999), p. 2223 [ISBN: 80-902724-3-6].

ISSN 2071-0194. Ukr. J. Phys. 2017. Vol. 62, No. 3 
8. P.E. Clarke, D. Field, D.F. Klemperer. Optical spectroscopic study of mechanisms in $\mathrm{CCl}_{4}$ plasma etching of $\mathrm{Si}$ Appl. Phys. 67, 1525 (1990) [DOI: 10.1063/1.345663].

9. V. Sharma. Momentum spectroscopic studies of atomic and molecular ionization. Ph.D. thesis (Mohanlal Sukhandia University, 2007).

10. E.G. Kostin, V.V. Ustalov, O.A. Fedorovich. Massspectrometry research of chemically active plasma in highfrequency discharge in controlled magnetic fields. Zbirn. Nauk Prats Inst. Yadern. Dosl. 2, No. 13, 86 (2004) (in Ukrainian).

11. O.A. Fedorovich, M.P. Kruglenko, B.P. Polozov. Peculiarity of plasma-chemical etching of silicon plate edges of photoelectric converters. Tekhnol. Konstr. Élektron. Apparat. No. 6, 46 (2009) (in Russian).

12. V.V. Hladkovskiy, O.A. Fedorovich, B.P. Polozov, M.P. Kruglenko. About peculiarities of self - bias voltage formation in plasma-chemical reactors with controlled magnetic fields. Probl. At. Sci. Technol. 1 (95), 156 (2015).

13. O.A. Fedorovich, V.V. Hladkovskiy, B.P. Polozov, M.P. Kruglenko. The bias voltage and its influence on the etching rate of silicon. Probl. At. Sci. Technol. 6 (100), 146 (2015).

14. A.N. Zaidel, Tables of Spectral Lines (Fizmatgiz, 1962) (in Russian).

15. A.R. Striganov, G.A. Odintsova, Tables of the Spectral Lines of Atoms and Ions (Énergoizdat, 1982) (in Russian).

16. R.W.B. Pearse, A.G. Gaydon. The Identification of Molecular Spectra (Chapman and Hall, 1976) [ISBN: 041214350X].
17. A.N. Zaidel, N.I. Kaliteevskii, L.V. Lipis, M.P. Chaika. Emission Spectrum Analysis of Atomic Materials (U.S. Atomic Energy Commission, 1963).

18. V.V. Hladkovskiy, B.P. Polozov, O.A. Fedorovich. Influence of bias voltage on the etching rate of silicon and formation of surface relief. In Proceedings of the 16th International Scientific and Practical Conference on Modern Information and Electronic Technologies (Odessa, 2015), p. 236 (in Russian).

Received 20.11.15

Translated from Ukrainian by O.I. Voitenko

В.В. Гладковсъкий, О.А. Федорович

СПЕКТРОСКОПІЧНІ ДОСЛІДЖЕННЯ

ПЛАЗМИ ВИСОКОЧАСТОТНОГО РОЗРЯДУ

ПРИ ПЛАЗМОХІМІЧНОМУ ТРАВЛЕННІ

ЕПТТАКСІАЛЬНИХ СТРУКТУР НІТРИДУ ГАЛІЮ

$\mathrm{P}$ е $з$ ю $\mathrm{M}$ е

Приведено результати експериментальних досліджень впливу напруги зміщення на еволюцію спектрів випромінювання плазми при травленні нітриду галію в плазмохімічному реакторі (ПХР) з керованими магнітними полями. При значеннях напруги зміщення більших за -250 В на спектрах випромінювання плазми з'являються лінії, що належать збудженим атомам матеріалів, з яких виготовлений робочий електрод. Під впливом від'ємного потенціалу проходить розпилення активного електрода і переосадження іонів металу на поверхню зразка, який обробляється, що приводить до зменшення швидкості травлення. 